\title{
FLORIDO DEL CORRAL, DAVID (Coord.) (2017) Las almadrabas suratlánticas andaluzas: historia, tradición y patrimonio (siglos XVIII-XXI). Sevilla: Editorial Universidad de Sevilla. 326 p.
}

\section{Alfons Garrido}

David Florido coordina "Las almadrabas suratlánticas andaluzas: historia, tradición y patrimonio (siglos XVIII-XXI)", en el que han participado, además, los investigadores Antonio Santos, Juan M. Ruiz y José A. López. El título del libro indica claramente la perspectiva que el autor da al análisis de este arte milenario, emblemático, casi icónico del litoral andaluz. A medio camino entre la historia y la antropología, pone de relieve una dimensión de la actividad pesquera en auge en el litoral español: la pesca como patrimonio.

Esta lectura de la pesca nos ha hecho reflexionar. Al autor de esta reseña le ha traído a la mente una comunicación que presentó hace unos años en Marsella, en la que se comparaban los distintos significados de hechos aparentemente similares: la pesca de grandes animales marinos mediante el uso de métodos "tradicionales". Se oponían la repugnancia y repulsa que generan hoy las imágenes de la pesca de delfines en la bahía de Taiji (Japón) con la bonita, estética e icónica “levantá” en una almadraba siciliana para la pesca del atún rojo del Mediterráneo. El mismo color del agua ensangrentada, los mismos gritos nerviosos de los pescadores, operaciones de captura similares... y connotaciones completamente distintas: "patrimonio mediterráneo" frente a "barbarie asiática". Ahí se defendía que en función del contexto, valores, símbolos y representaciones en un momento dado de su historia, la sociedad decide crear "su patrimonio", escoge aquello a lo que le otorga el valor necesario como para que merezca ser preservado, documentado, 
difundido y recreado, con el objetivo de cohesionar, singularizar, reivindicar y permitir la reproducción de una comunidad.

Entre las muchas manifestaciones culturales marítimas, la sociedad andaluza le ha otorgado a la almadraba una importancia patrimonial relevante y singular, un puesto de honor. Arte de origen incierto - quizá fenicio -, se propagó por todo el Mediterráneo para la captura del preciado atún rojo (Thunnus thynnus) durante la migración estacional de este animal. De las centenares de almadrabas instaladas a lo largo de los siglos en aguas mediterráneas y atlánticas, hoy se mantienen sólo 20 en activo, repartidas entre España, Portugal, Italia y Marruecos. En España su distribución se registra en el litoral suratlántico: Tarifa, Zahara, Barbate y Conil, si bien subsisten almadrabas de pequeñas dimensiones, tanto en La Azohía (Murcia), como en Ceuta. Considerado un arte ecofriendly por la Unión Europea, su presente es incierto y su futuro algo oscuro. Sujetas a la crisis del atún, en los últimos años las capturas de las almadrabas se han reducido hasta mínimos históricos.

En este marco, Florido del Corral, uno de los mayores especialistas sobre este arte y esta cultura, reflexiona en este trabajo sobre la "tradición" y el proceso de patrimonialización de las almadrabas andaluzas, en un viaje desde su pasado de Antiguo Régimen - aquel "finibusterre de la picaresca" de Cervantes - hasta los imponentes y diversos retos actuales. Para ello examina diferentes elementos históricos, técnicos y culturales que justifican, en última instancia, la necesidad de preservar la cultura de la almadraba para generar identidad social. Lo hace desde una perspectiva etnohistórica y con un profuso conocimiento de los distintos procesos que llevan el pescado del arte al plato. Con ello, pone de relieve, en el marco de una progresiva e imparable mercantilización, las continuidades y los cambios que han sufrido los métodos, instituciones, valores y prácticas asociadas a este arte milenario.

Los historiadores de la pesca estamos en deuda con el gremio de antropólogos por su interés y esfuerzo por desempolvar la historia del sector pesquero. Dado el escaso interés por la pesca de la Historia como disciplina, la Antropología está llenando ese vacío. En el caso que nos ocupa, David Florido y Antonio Santos hacen en los primeros capítulos un esfuerzo historiográfico muy notable por recuperar la larga, convulsa y vibrante historia de las almadrabas durante el largo fin del Antiguo Régimen y su tránsito al capitalismo. Una historia que, obviando deliberadamente los períodos antiguo y medieval -que se nos antojan ricos pero poco estudiados-, se centra en la evolución de las almadrabas desde los siglos XVII y XVIII hasta la actualidad. De la Casa Ducal de Medina Sidonia, de donde utiliza abundante documentación, hasta la intervención cada vez más decidida del Estado en cuestiones pesqueras, atraviesa periodos de expansión alternados con otros de retraimiento. Sin duda, un momento crucial es la transición hacia las almadrabas 
fijas, de buche - gracias a la llegada de capitales valencianos, gallegos e italianos-, y la creación en 1928 de una institución central para la historia contemporánea de la pesca española del atún: el Consorcio Nacional Almadrabero. El CNA, ese monopolio público-privado, significó concentración empresarial, racionalización productiva, proletarización y consolidación de pueblos-factoría, pero también transformación de numerosos elementos tradicionales de las culturas del trabajo de las almadrabas que generaron no pocas quejas y conflictos.

El tránsito a la modernidad, con la recuperación de las almadrabas gaditanas tras la disolución del Consorcio Almadrabero en 1971, muestra la voluntad del territorio, casi a contracorriente haciendo frente a grandes contratiempos, de mantener esta industria. En esa continuidad histórica, un salto adelante fue la entrada en el negocio de las empresas congeladoras japonesas, empresas que han exprimido el atún rojo hasta límites peligrosos. Hoy los avatares del mercado obligan a las empresas almadraberas - con sus métodos de captura tradicionales y sus cuotas restringidas - a adaptarse a nuevas lógicas productivas y comercializadoras (métodos de captura, cámaras congeladoras, engorde en granjas, despiece en tierra, marcas de garantía) con el objetivo de defender al atún andaluz y sus almadraberos de los vaivenes de la lonja japonesa y de lógicas capitalistas cada vez más globales, veloces y cambiantes. Todo ello queda muy bien reflejado en este trabajo.

Llegados al presente, el autor apunta que los numerosos y difíciles retos para la viabilidad de las almadrabas atlánticas - recordemos que ICAAT apunta a una reducción de las poblaciones de atún rojo del $80 \%$ en apenas treinta años, o un riesgo claro de deslocalización hacia Marruecos, con costes menores- se dirimen sobre todo en la arena política y en la dimensión tecnológica, hecho que tiene una afectación especial sobre un contingente laboral "excesivo". Todo parece indicar que la captura global del atún está sobrecapitalizada y en decrecimiento, peligro que se extiende a la industria almadrabera actual y que requiere una negociación política constante en los órganos multinacionales que distribuyen las cuotas de pesca. La sensación es que los derechos históricos no están siendo respetados.

En la segunda parte del libro, el historiador aprende del antropólogo en capítulos dedicados a la reconstrucción de los sistemas de conocimiento ligados a la almadraba y al análisis de sus instituciones. Aquí la perspectiva histórica es necesariamente menor. Los autores ponen de relieve, a partir de las entrevistas que tanto Juan M. Ruiz como José A. López y D. Florido han realizado a capitanes y otro personal técnico de las almadrabas. la importancia para la cultura del trabajo almadrabera de la transmisión y apropiación de los sistemas de conocimiento experto y la capacidad de mando de los "artífices intelectuales", los capitanes: un conocimiento "tradicional" dinámico, adaptado al entorno, transgeneracional, que se ajusta permanentemente y que sabe beber de todas las fuentes, incluso la científica. Los autores se detienen para ello, en la descripción de 
un proceso clave para el éxito de la empresa pesquera: aprovisionamiento, diseño y calamento del arte. El uso de las fuentes orales enriquece el discurso y da viveza a un relato que cautiva por la naturalidad de sus protagonistas.

Hoy la tecnología y las necesidades del mercado condicionan en extremo tareas antiguamente sujetas a la intuición, entrenamiento, arrojo o la fuerza bruta. También se pierden formas singulares de comunicación asociadas a las distintas tareas pesqueras, como el "salomar" o las tallas. Con todo, los medios intelectuales de producción conforman un corpus de habilidades y conocimientos prácticos, fugaces y personales, un habitus incorporado que se manifiesta en las marcas, en la visualización del pescado, en el armamento del arte o en la relación de los capitanes con los marineros y empresas pesqueras: conocimientos flexibles, informales, contextuales que sólo a los más "espabilaos" les permite ascender en la escala socio-laboral para llegar a ser capitanes. Para ello no hay manuales ni formación académica.

La perspectiva histórica que predomina en este estudio permite analizar los cambios en la organización almadrabera y la vigencia actual de las instituciones que rigen su economía. Interesante nos ha parecido el análisis del "robo de pescao", práctica inveterada en las almadrabas desde antiguo y que Florido interpreta como una recompensa "permitida" al trabajador en el marco del principio de reciprocidad, una reclamación "de lo que se considera propio". A la hora de analizar el sistema retributivo, el autor choca con las dificultades que imponen su carácter mixto o sus cambios a la luz de la economía política de la almadraba.

La densidad de elementos patrimoniales singulares en las almadrabas andaluzas es espectacular. A lo largo del texto, los autores lo corroboran ampliamente, pese a reconocer que su selección en este libro es, necesariamente, restrictiva. Termina su análisis tratando los ritos, ofrendas votivas y fiestas asociadas a la cultura pesquera, forjadas del trasiego continuo de trabajadores de distintos lugares; unas manifestaciones, pese a todo, en franca decadencia, que se pierden con la memoria de los antiguos habitantes de los pobladosfactoría. Rituales de inicio de temporada o quema de Juan y Juana están atravesados de elementos simbólicos, políticos y económicos que el autor aúna y relaciona para mostrar los cambios en sus significados a la par que la almadraba, como industria y como cultura, se marchita. La lógica empresarial no deja ya mucho espacio a otras manifestaciones más simbólicas.

Este recorrido etnohistórico por las almadrabas atlánticas andaluzas contiene elementos esenciales para su compresión, no solo como industria pesquera milenaria, sino en el contexto de los enormes retos y los potentes cambios socioeconómicos que está sufriendo. Por ello, Florido propone que al proceso de patrimonialización al que están siendo sujetas las almadrabas - a partir de numerosas iniciativas públicas - no se le dé un exclusivo valor de cambio en el contexto turístico, como mero reclamo al consumo, 
sino que sirva para su "revalorización social, cultural y política". Ello ha de permitir la reconstrucción de la memoria y reproducción social de la almadraba. Algunos signos esperanzadores apuntan en esta dirección.

En otras regiones españolas, las almadrabas se dejaron morir y hoy apenas hay recuerdo de ello. Pensamos en Cap de Terme, en la costa de Tarragona. Su litoral era una "fábrica de atunes", como lo llamaban la población local. Por ello se instaló desde el siglo XIX una almadraba, al cobijo de la cual nació otro barrio-factoría. Hoy es una urbanización repleta de turistas holandeses. Apenas hay recuerdo, un topónimo, pero ninguna mención a su origen ni función. En Andalucía, en los últimos cincuent años también se han perdido numerosos componentes de la cultura almadrabera, pero las almadrabas se mantienen, pese a todo: no sólo su recuerdo, siguen vivas después de tres mil años. Por ello tiene especial valor este trabajo que mediante las herramientas del historiador y el discurso del antropólogo, trabaja para valorizar esta cultura más allá de su mera "turistificación" y para ponerla al servicio de la comunidad: el patrimonio como carácter vivo y activo, esperanzador. Sin duda una mirada necesaria a la pesca. Los muchos cambios forjan la tradición, entendida no como algo estático, sino mutante y adaptativo. Su valor no es solo económico, sino que se asienta en la sostenibilidad, en la responsabilidad, el compromiso y el respeto por el territorio y su gente. 